\title{
Pozitif ve Negatif Duyguların Ayrımında Etkili EEG Kanallarının Dalgacık Dönüşümü ve Destek Vektör Makineleri ile Belirlenmesi
}

\author{
Araştırma Makalesi/Research Article
}

\author{
Talha Burak ALAKUŞ ${ }^{1 *}$, ID İbrahim TÜRKOĞLU² \\ ${ }^{1}$ Yazılım Mühendisliği Bölümü, Kırklareli Üniversitesi, Kırklareli, Türkiye \\ ${ }^{2}$ Yazılım Mühendisliği Bölümü, Fırat Üniversitesi, Elazığ, Türkiye \\ burak.alakuss@gmail.com, iturkoglu@firat.edu.tr \\ (Geliş/Received:15.11.2018; Kabul/Accepted:02.07.2019)
}

DOI: $10.17671 /$ gazibtd.482939

\begin{abstract}
$\ddot{O}_{z}$ et - Duygular kişilerin yaşamlarını ve karar verme mekanizmalarını hayatının tamamında etkilemektedir. İnsanlar duygulara kelimeleri, sesleri, yüz mimiklerini ve vücut dillerini kullanarak istemli ya istemsiz bir şekilde, iş yaparken, gözlemlerken, düşünürken kısacası çevresiyle iletiş̧im kurarken başvururlar. Bundan dolayı, duyguların davranışlarını analiz etmek ve anlamak büyük önem arz etmektedir. Beyin sinyallerine dayalı gerçekleştirilen duygu tahmini günümüzde Beyin-Bilgisayar Arayüzü (BBA) uygulamalarında büyük yarar sağlamaktadır. BBA uygulamaları daha çok sağlık, eğitim, güvenlik, sanal gerçeklik, bilgisayar oyunları olmak üzere birbirinden farklı birçok alanda kullanılmaktadır. Ancak, beyin sinyallerinin elde edilmesi sırasında gürültülerin ortaya çıkması, EEG kanallarının yanlış seçilmesi, verilerin yoğun olması ve uygun olmayan özellik çıkarım yöntemlerinin kullanılması, BBA uygulamalarının yeterli seviyeye gelememelerine neden olmaktadır. Bu çalışmada, hangi EEG kanallarının pozitif-negatif duyguların ayrımında etkili olduğu belirlenmeye çalışılmış ve DEAP veri setindeki 32 kanallı EEG sinyalleri kullanılmıştır. Özellik çıkarım aşamasında, dalgacık dönüşümü, bilgi ölçüm yöntemleri ve istatistiksel yöntemler kullanılarak etkili EEG kanallarının belirlenmesi hedeflenmiștir. Çalıșmanın son aşamasında ise, elde edilen özelliklerden yola çıkılarak oluşturulan eğitim kümesi DVM (Destek Vektör Makineleri) kullanılarak sınıflandırılmıştır. Önerilen yöntemin sınıflandırma performansı, sınıflandırma kesinliği, log-kaybı ve on kat çapraz-doğrulama) ile belirlenmiştir. Her bir EEG kanalı için doğruluk oranı hesaplanmış ve ortalama başarım $\% 74$ olacak şekilde gözlemlenmiştir. Önerilen yöntem ve tekniklere göre en etkili EEG kanalları Fp1, FC6, C4, CP1, CP5, CP6, T7, P7 ve Pz olarak belirlenmiștir.
\end{abstract}

\section{Determination of Effective EEG Channels for Discrimination of Positive and Negative Emotions with Wavelet Decomposition and Support Vector Machines}

\begin{abstract}
People's lives and decision-making process are influenced by negative-positive emotions. People state their emotions with words, body language, facial expression and voice during thinking, decision making, observing or interacting with the environment. So, it is vital to understand the nature of emotions well. EEG based emotion recognition systems are useful in brain-computer interface (BCI) area. BCI systems are applied in various fields such as education, healthcare systems, virtual reality, video gaming industry. Although EEG signals give much valuable information about brain functions and emotions, brain-computer interface systems have not attained the targeted goals because of artefacts, misuse of EEG channels, data complexity and inappropriate feature extraction and selection methods. In this article, we tried to analyze which EEG channels are effective to estimate positive-negative emotions. We applied publicly available dataset (DEAP) in this work and 32 different EEG channels were classified. Discrete wavelet decomposition, information measurement and statistical methods were applied in the feature extraction phase. In the last phase, SVM (Support Vector Machines) are applied in order to classify the features. The classification performance of the proposed method evaluated by classification accuracy, log-loss, and ten-fold cross validation. Performance accuracy was observed from each EEG channel and average accuracy was found $74 \%$. The experimental results indicated that the best EEG channels for positivenegative emotions Fp1, FC6, C4, CP1, CP5, CP6, T7, P7, and Pz via the proposed method.
\end{abstract}

Keywords - emotion recognition, support vector machines, wavelet decomposition, entropy 


\section{GİRİS (INTRODUCTION)}

Duygu, dış uyaranlara karşı gösterilen tepki ya da bilinç olarak tanımlanmaktadır. İnsanların rutin yaşantılarını etkilediği için günlük hayatta önemli bir rol oynamaktadır. Mutluluk, öfke, hüzün gibi temel duygular kişiler tarafından sürekli yansıtılmakta ve bu durum insanların toplum üzerindeki konumunu önemli derecede etkilemektedir. Negatif duygulara sahip olan kişiler toplum tarafından olumsuz karşlanmakta ve bu durum kişilerin sadece fizyolojik olarak değil aynı zaman da psikolojik olarak da sağlıksız olmalarına neden olmaktadır [1]. Duygu tahminine yönelik çok sayıda araştırma bulunmakta ve duyguların davranışlarının anlaşılması hedeflenmektedir. Duyguların soyut olması ve kişiden kişiye değişiklik göstermesi çalışmaların verimli olamamasına neden olmaktadır. Ayrıca çok sayıda veri toplama (yüz mimikleri, beyin sinyalleri, ses işaretleri, vücut dili vb.) ve veri analizi yöntemlerinin olması sonuçların karmaşık olmasına neden olarak verilerin uzun sürede işlenmesine sebebiyet vermektedir. $\mathrm{Bu}$ gibi nedenlerden dolayı bilgisayar tabanlı ve makine öğrenmesine dayalı bir sisteme ihtiyaç duyulmaktadır [2]. Duygular, ses işaretleri, yüz mimikleri, fiziksel aktiviteler ya da vücut dili ve fizyolojik sinyaller olmak üzere birbirinden farklı yöntemlerle elde edilmektedir. İnsanlar dış dünyayla iletişim kurarken ve duygularını aktarırlarken ses işaretlerinden ve kelimelerden yararlanmaktadırlar. Sesin yoğunluğu, gücü, konuşma seviyesi ve konuşma hızı analiz edilerek duygu tahmini gerçekleştirilmektedir [3] Duyguları elde etmede kullanılan ve uygulaması kolay olan diğer bir yöntem ise yüz mimiklerine dayanmaktadır. $\mathrm{Bu}$ yöntemde denekler kameranın karşısına geçmekte ve kişilerin tepkileri gözlemlenmektedir. Ayrıca vücut dili ve fiziksel hareketlerde kişilerin duygularını yansıtmaktır. Örneğin, sinirli bir insan dudaklarını birleştirirken, canı sıkılan bir insan camdan dışarı bakmakta ya da ayaklarını birbirine vurmaktadır [4]. Ancak bu yöntemle elde edilen verilerin sürekli manipüleye uğraması verilerin eksik ve güvenilir olmamasına neden olmaktadır. İnsanlar mimiklerini, ses tonlarını ve hareketlerini kolay bir şekilde taklit edebilmektedirler. Bundan dolayı daha güvenilir bir sistemin gereksinimi doğmuş ve fizyolojik sinyallerin önemi artmıştır [5]. Duygu tahmininde en çok kullanılan sinyaller EDA (Elektrodermal Aktivite), GDT (Galvanik Deri Tepkisi), EKG (Elektrokardiyogram) ve EEG (Elektroensefalografi) yöntemleriyle elde edilen sinyallerdir [6]. Kullanımı kolay, maliyeti ucuz ve son zamanlarda taşınabilir teknolojiyle bağlantılı olması nedeniyle literatürde en yaygın kullanılan yöntemi EEG sinyallerine dayanarak gerçekleştirilen yöntemlerdir [7].

\subsection{Duygu Modelleri (Emotion Models)}

Ayrık ve boyutsal olmak üzere iki çeşit duygu modeli bulunmaktadır. Ayrık duygu modeli pozitif ve negatif olmak üzere altı ana duygudan (sinir, korku, hüzün, nefret, neşe ve hayret) meydana gelirken [13], boyutsal modelde duygular isimleriyle değil uyarılma-valans düzlemindeki konumlarıyla ifade edilirler [14]. Uyarılma-valans düzleminde duygular dört faklı bölgeye ayrılmıştır. Valans ekseni negatif-pozitif duyguları belirtmekte ve bu duygular eksenin her iki tarafına ayrı bir şekilde tanımlanmıştır. Valans ekseninin sol tarafı negatif duyguları ifade ederken, sağ tarafta ise pozitif duygular bulunmaktadır. Uyarılma ekseninde ise duygular, aşağıdan yukarıya doğru aktif olmayan duygulardan aktif olan duygulara doğru sıralanmıştır. Şekil 1'de uyarılma-valans düzlemine ait duygu modeli gösterilmiştir.

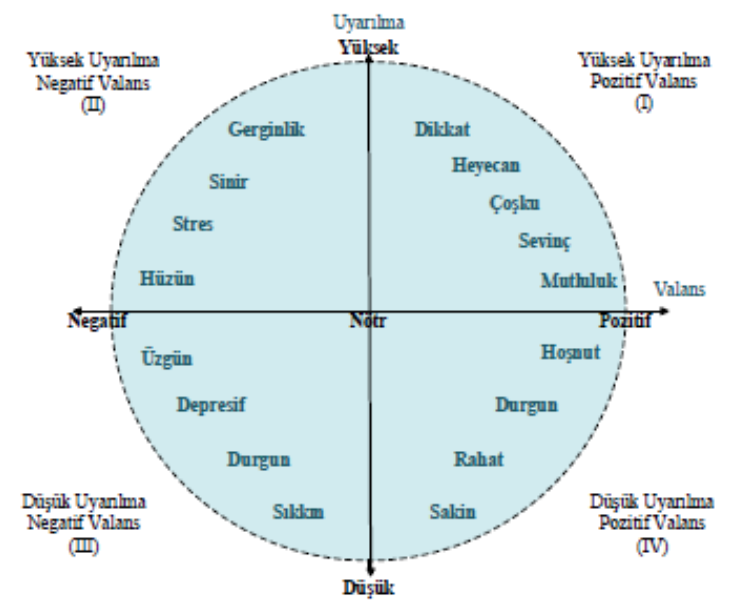

Şekil 1. Uyarılma-valans duygu düzlemi (Arousal-valence emotion plane) [5]

Düzlemde YUPV (Yüksek Uyarılma Pozitif Valans), YUNV (Yüksek Uyarılma Negatif Valans), DUNV (Düşük Uyarılma Negatif Valans) ve DUPV (Düşük Uyarılma Pozitif Valans) olmak üzere 4 farklı bölge bulunmaktadır. $\mathrm{Bu}$ model yapısında duygular isimleriyle değil koordinat düzlemindeki bölgelerine göre ifade edildikleri için evrensel bir modeldir. Bu model şeklinde, üzgün duygusu artık üzgün olarak değil DUNV şeklinde ifade edilmektedir. Evrensel bir model olduğu ve diğer çalışmalarla kıyaslanabilmesi için bu çalışmada bahsi geçen model üzerinde durulmuştur.

Makalenin 2. Kısmında beyin sinyallerine dayalı gerçekleştirilen duygu analizine yönelik birkaç makale incelenmiş ve kullanılan yöntemler ve başarımları değerlendirilmiştir. 3. Kısımda bu çalışmada kullanılan yöntemler açıklanmış ve kullanılan veritabanına ait tekniksel bilgilere yer verilmiştir. 4. Kısımda elde edilen başarım sonuçları gösterilmiş, önerilen yöntem ile etkili 
olan EEG kanalları belirlenmiş ve geleceğe yönelik fikirlere değinilmiştir.

\section{2. İLGILI ÇALIŞMALAR (RELATED WORKS)}

Literatür incelendiğinde çok sayıda EEG sinyallerine dayalı duygu analizi çalışmalarının olduğu gözlemlenmiştir. Bu kısımda, bu makale ile aynı EEG verisetini kullanan çalışmalara değinilmiş ve başarımları ile önerilen yöntemler karşıllaştırılmıştır.

Qiang Zhang ve diğ. [15] önerdikleri metotta DEAP veritabanını kullanarak duygu ayrımı gerçekleştirmişlerdir. Uyarılma-valans düzlemi üzerinde çalışmayı gerçekleştirmişler ve derin öğrenme kullanmışlardır. Seyrek Otomatik Kodlayıcı kullanarak özelliklerin öğrenilmesini hedeflemişler ve ardından lojistik regresyon yöntemi ile özellikleri elde etmişlerdir. Sınıflandırma aşamasında ise Derin Otomatik Kodlayıcı kullanılmış ve uyarılma-valans düzlemi sınıflandırılmıştır. Valans için \%85,2 uyarılma için ise \%80,78 oranında başarım elde edilmiştir.

Ahmet Mert ve Aydın Akan [16] yapmış oldukları çalışmada Çok Değişkenli Senkrosıkıştırma Dönüşümünü kullanarak özellik çıkarımı yapmışlardır. ÇDSD kullanarak ilk başta sinyallerdeki titreşimler ortaya çıkarılmış ve ardından Bağımsız Bileşen Analizine (BBA) ve özellik çıkarım yöntemine başvurulmuş, bu sayede özellik boyutu indirgenmiştir. Sınıflandırma işlemi için YSA (Yapay Sinir Ağları) kullanılmış ve uyarılma-valans düzlemi için sırasıyla $\% 82,11$ ve $\% 82,03$ oranında başarımlar elde edilmiştir. Gerçekleştirmiş oldukları çalışmada veritabanı için DEAP'tan yararlanmışlardır.

Yong Zhang ve diğ. [8] önerdikleri çalışmada DEAP verisetine ait hazır EEG verileri kullanılmış ve boyutsal model üzerinde duygu analizi işlemi gerçekleştirilmiştir. Yapılan boyutsal model analizinde duygular uyarılma ve valans kümelerine ayrıştırılmıştır. Çalışma kapsamında 32 EEG kanalı değerlendirmek yerine araştırmacılar 2 EEG kanalı üzerinde durmuş ve tüm işlemleri F3 ve C4 kanalı üzerinden gerçekleştirmiş̧lerdir. Boyutsal modelde bulunan dört bölge de (YUPV, YUNV, DUPV ve DUNV) sınıflandırma işlemi için değerlendirilmiştir. Anahtar özelliklerin belirlenmesi için ise ampirik mod ayrışımı kullanılmış ve dört adet içsel mod işlevi elde edilmiştir. Ardından her içsel mod işlevi üzerinde örnek entropi değerleri hesaplanmış ve öznitelik vektörü oluşturulmuştur. Sınıflandırma aşamasında ise DVM kullanılmış ve çalışma çoklu-sınıf ve ikili-sınıf şeklinde ayrılmıştır. İkili-sınıf ile gerçekleştirilen çalışmanın başarımı \%94,98 olarak elde edilirken çoklu-sınıf ile bu başarım \%93,20 olacak şekilde gözlemlenmiştir.

Li Xin ve diğ. [17] İlgililik Vektör Makineleri (IVM) ve destek vektör makineleri kullanarak duygu analizini gerçekleştirmişlerdir. DEAP veritabanındaki EEG sinyalleri kullanılmış ve pozitif-negatif duyguların ayrımı yapılmıştır. Özellik çıkarım aşamasında örnek entropi ve çok-ölçekli entropiye başvurulmuştur. Özellik vektörünün elde edilmesinin ardından özellikler RVM ve DVM de sınıflandırılmak üzere kullanılmıştır. Sonuç olarak RVM ile \%93,33 oranında başarım elde edilirken, bu başarım DVM ile azalmış ve sınıflandırma performansı $\% 78,67$ olacak şekilde gözlemlenmiştir.

Celia Shahnaz ve diğ. [9] gerçekleştirdikleri çalışmada duygu analizi yapılmış ve bu işlem için DEAP verisetine başvurulmuştur. Özelliklerin elde edilmesi aşamasında ampirik mod ayrışımına başvurulmuş ve 3 adet içsel mod işlevi elde edilmiştir. Elde edilen bu içsel mod işlevleri üzerinde dalgacık dönüşümü uygulanmış ve dalgacıklar üzerinden basıklık, varyans ve eğrilik değerleri hesaplanarak özellik kümesi oluşturulmuştur. Oluşturulan bu özellik kümesinin boyutunu azaltmak için ise parçacık bileşen analizi uygulanmış ve analiz işleminin ardından sınıflandırma işlemi gerçekleștirilmiştir. Sınıflandırma işlemi için DVM kullanılmış ve valans, uyarılma, beğeni ve baskınlık için sırasıyla $\% 67, \% 72, \% 66,51, \% 70,52$ ve $\% 66,88$ oranında başarım elde edilmiştir.

Nitin Kumar ve diğ. [10] DEAP verisetini kullanarak duygu sınıflandırma işlemi gerçekleştirmişler ve bunun için çalışmada bispektral analizine dayalı bir yöntem önerilmiştir. Sınıflandırma işlemi için uyarılma/valans düzlemi kullanılmış ve sadece belirli EEG kanalları çalışmaya dâhil edilmiştir. Bu kanallar kafa yapısının alın bölgesine denk gelen $F_{p} 1$ ve $F_{p} 2$ kanal çiftleridir. Özellik çıkarım aşamasında kanallardan bispektrum değerleri elde edilmiş ve buna bağlı olarak 5 adet özellik toplanmıştır. Sınıflandırma işlemi için DVM kullanılmış ve doğrulama adımında 10-katlı çapraz doğrulama yapılmıştır. Çalışmanın sonunda valans için \%61,17 oranında başarım elde edilirken uyarılma için \%64,84 oranında sonuç gözlemlenmiştir.

Jirayucharoensak Suwicha ve diğ. [11] önerdikleri metotta derin öğrenme kullanılmış ve DEAP verisetinden elde edilen EEG verileri duygu analizi işlemi için değerlendirilmiştir. Sınıflandırma işlemi için uyarılma ve valans düzlemi üzerinde durulmuş ve bu iki sınıf için performans sonuçları irdelenmiştir. Farklı farklı parametrelerde deneysel çalışmalar gerçekleştirilmiş ve birbirinden farklı dört yöntemin sonucu çalışmada kıyaslanmış ve en iyi sonucu veren yöntemin bulunması hedeflenmiştir. Birinci yöntemde 100 nörondan oluşan derin öğrenme mimarisi, ikinci yöntemde 50 nörondan oluşan derin öğrenme mimarisi, üçüncü yönteme parçacık bileşen analizi ve 50 nörondan oluşan derin öğrenme mimarisi ve dördüncü yöntemde parçacık bileşen analizi, eş değişken adaptasyonu ve 50 nörondan oluşan derin öğrenme mimarisi tasarlanmıştır. Yapılan sınıflandırma işleminin ardından en iyi sonucu dördüncü yöntem vermiş ve ortalama başarım valans ve uyarılma için $\% 53,42$ ve $\% 52,03$ olarak bulunmuştur. 
Shiyi Wu ve diğ. [12] önerdikleri yöntemde DEAP veriseti kullanılmış ve $\mathrm{F}_{\mathrm{p}} 1$ ve $\mathrm{F}_{\mathrm{p}} 2$ EEG kanallarından duygu tahmini işlemi gerçekleştirilmiştir. Özellik çıkarım aşamasında hızlı Fourier dönüşümü ve dalgacık dönüşümü kullanılmıştır. Fourier dönüşümü ile beş farklı frekansa ait EEG verileri üzerinden özellikler toplanmış ve bunun için alt sinyallerin entropi, spektral asimetri indeksi ve asimetri değerleri hesaplanmıştır. Dalgacık dönüşümü işlemi için ise Daubechies filtresine başvurulmuş ve 6. Dereceden filtre uygulanarak EEG sinyalleri alt sinyallere dönüştürülmüştür. $\mathrm{Bu}$ alt-sinyallerden ise maksimum, minimum, standart sapma ve dalgacık katsayılarının ortalaması olmak üzere dört farklı özellik elde edilmiştir. Elde edilen özelliklerin rastgele seçilmesiyle bir eğitim seti oluşturulmuş ve bu eğitim seti gradyan artırma karar ağacı ile sınıflandırılmıştır. Boyutsal duygu modeli üzerine gerçekleştirilen bu çalışmada sadece valans değerleri hesaplanmış ve ortalama başarım \%75,18 olarak bulunmuştur.

\section{MATERYAL VE YÖNTEMLER (MATERIAL AND METHODS)}

Bu çalıșmada DEAP [20] verisetine ait veriler kullanılmış ve veritabanında bulunan 32 adet EEG kanalının hepsi değerlendirilmiştir. Çalışmanın ilk aşamasında 32 kanaldan elde edilen tüm sinyaller ayrık dalgacık dönüşümü aracılığıyla alt sinyallere dönüştürülmüştür. $\mathrm{Bu}$ işlem için dalgacık filtresi olarak 2.dereceden Daubechies kullanılmış ve sinyaller 4 seviye ayrıştırılmıştır. Bu yolla farklı frekanstan sinyaller elde edilmiştir. Özellik çıkarım aşamasında ise, istatistiksel yöntemlere (en yüksek değer, en düşük değer, ortalama değer) ve bilgi ölçüm (log enerji entropi, Higuchi Fraktal Boyutu) yöntemlerine başvurulmuştur. Önerilen yöntemin son kısmında ise elde edilen özellikler destek vektör makinelerinde sınıflandırılmak üzere kullanılmış ve her bir EEG kanalının başarımı değerlendirilerek etkili kanallar belirlenmiştir. Şekil 2'de önerilen yönteme ait çalışma adımları verilmiştir.

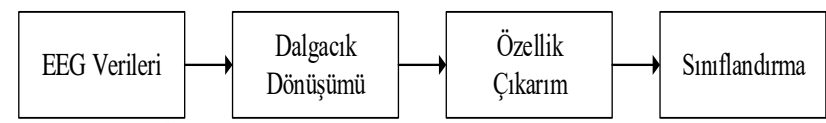

Şekil 2. Önerilen yöntemin akış şeması (Flowchart fort he proposed method)

\subsection{EEG Veritabanı (EEG Database)}

$\mathrm{Bu}$ çalışmada DEAP verisetine ait EEG verileri kullanılmıştır. Son kullanıcı anlaşması ve formları imzalanarak internet üzerinden elde edilen bu veritabanında 32 EEG kanalı bulunmakta ve duygular uyarılma-valans düzlemine göre elde edilmiştir. Verilerin elde edilmesi aşamasında görsel-işitsel uyaranlar (müzik klipleri) kullanılmış ve toplam 32 denekten sinyaller elde edilmiştir. Çalışma boyunca 120 klip kullanılmış ancak değerlendirme için sadece 40 tanesine başvurulmuştur. Her bir denek bu videoları bilgisayar ekranı aracılığıyla belirli bir süreyle dinlemiş ve izlemiş ve o esnasında deneklerden beyin sinyalleri toplanmıştır. Her bir video ya da deneme için verilerin elde edilme aşaması 2 dakika olacak şekilde tasarlanmıştır [20]. Verilerin elde edilme aşamasının görseli Şekil 3 ’te verilmiştir.

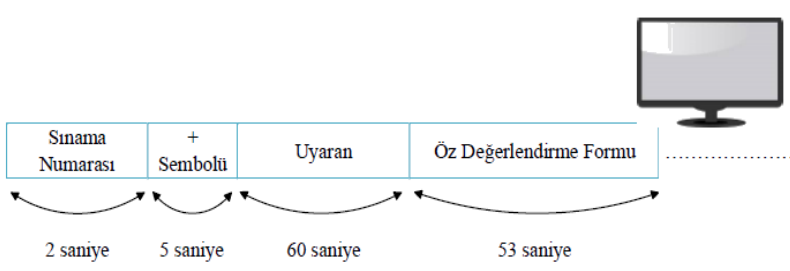

Şekil 3. DEAP verilerinin elde edilme yöntemi (Data acquisition method in DEAP) [21]

Şekil 3 'te de görüldüğü üzere, 2 sn. boyunca ekrana video ya da deneme numarası gösterilmiş ve bu sayede denekler kaçıncı videoda olduklarını bilmişlerdir. Ardından 5 sn. boyunca ekran '+"' simgesi gösterilmiş ve bu sayede deneklerin ekrana odaklanması hedeflenmiştir. Odaklanma işleminin sonrasında, $60 \mathrm{sn}$. boyunca ekrana uyaran verilmiş ve bu esnada denekler uyarana bakarken EEG verileri toplanmıştır. Son olarak ise geri kalan süre boyunca deneklerin Öz Değerlendirme Formu (ÖDF) 'nu doldurmaları beklenmiştir. Elektrotlar 10-20 elektrot sistemine göre yerleştirilmiş ve önce frekans değerleri 512 Hz. Olacak şekilde verileri toplanmıştır. Ancak önişlemden geçirilen sinyaller $128 \mathrm{~Hz}$. Ye kadar düşürülmüştür. Bu çalışmada önişlemden geçirilmiş EEG verileri kullanılmıştır. Çalışmada kullanılan EEG kanalları Şekil 4'te verilmiştir.

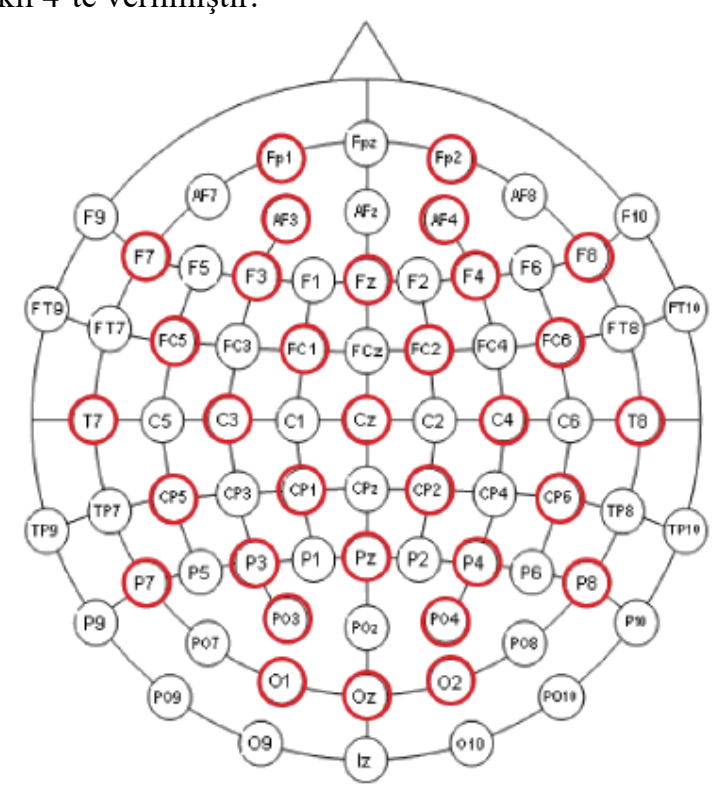

Şekil 4. Çalışmada kullanılan EEG kanalları (EEG channels used in this work) [21]

ÖDF toplanan EEG sinyallerinin doğruluğunu ve güvenilirliğini ölçmek amacıyla gerçekleştirilen anket şeklinde bir formdur. Bu formda 4 adet değişken (uyarılma, 
valans, hâkimiyet, beğeni) bulunmakta ve parametreleri 19'a olacak şekilde değişiklik göstermektedir (beğeni hariç). $\mathrm{Bu}$ derecelendirme ile deneklerin, o uyaran için hissetmiş olduğu duygu analiz edilmekte ve bu sayede EEG verisi o hisse göre değerlendirilmektedir. 5 numaralı Şekil'de ÖDF örneği gösterilmiştir.

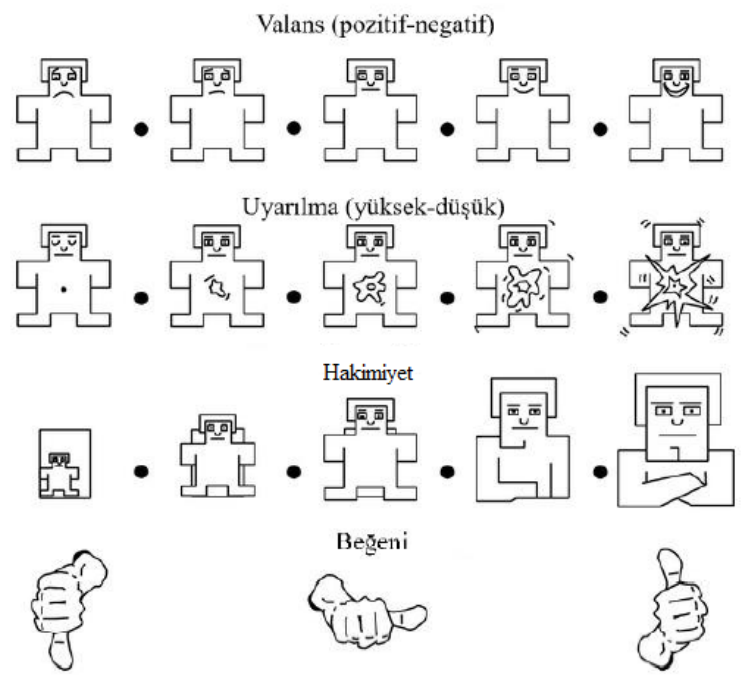

Şekil 5. Öz-değerlendirme formu örneği (Example of selfassessment manikin) [21]

Valans değişkeni kişilerin uyarana karşı hissetmiş oldukları durumu ifade etmektedir. Parametre değeri 1'den 9'a kadar olup en düşük puan mutsuzluğu, en yüksek puan ise mutluluğu ifade etmektedir. Derecelendirme puanının 5'ten düşük olması düşük valans değerini, 5'ten büyük olması yüksek valans değerini ve 5 olması ise valans değerinin nötr olmasını ifade etmektedir. Uyarılma parametresi ise uyarana karşı gösterilen tepki olarak belirtilmektedir. Aynı valans değişkeninde olduğu gibi bu değişkende 1-9 arası değer almaktadır. En düşük puan sakin hali ifade ederken, en yüksek değer heyecanlı hali ifade etmektedir. Derecelendirme puanının 5'ten düşük olması düşük uyarılmayı, 5'ten büyük olması yüksek uyarılmayı ve 5 olması ise nötr olmasını ifade etmektedir. Hâkimiyet parametresi uyarana karşı gösterilen itaat durumunu ifade etmektedir. Değerin 1 olması kişinin bu uyarana hâkim olmadığını belirtirken, 9 olması tamamen hâkim olduğunu göstermektedir. Beğeni parametresi deneklerin uyaranı beğenip beğenmediğini kontrol etmek amacıyla yapılır. Belirli bir sayı aralığı yoktur ancak şekillerle ifade edilirler. Başparmağın aşağı yöne bakması uyaranın beğenilmediğini, yukarı bakması ise beğenildiğini gösterir.

\section{2. Özellik Çıkarım Yöntemleri (Feature Extraction Methods)}

Çalışmada özellik çıkarım aşaması için dalgacık dönüşümü, istatistiksel yöntemler ve bilgi ölçüm yöntemlerine başvurulmuştur. Öncelikle EEG sinyalleri dalgacık dönüşümünden geçirilerek ayrık dalgacıklara ve frekanslara dönüştürülmüş, ardından her dalgacıktan özellik vektörü elde edilmiştir. Bu kısımda özelliklerin elde edilmesi için kullanılan yöntemlere değinilmiş ve açıklamaları verilmiştir.

\subsubsection{Dalgacık Dönüşümü (Wavelet Decomposition)}

Sinyal işleme alanlarında gerçekleştirilen çalışmalarda, frekans-alanına ait özelliklerin, zaman-alanına ait özelliklerden daha fazla bilgi verdiği gözlemlenmiştir [18]. Bundan dolayı dalgacık dönüşümü, dalgacık paket dönüşümü gibi yöntemler sinyal işleme alanında önem arz etmektedir. Dalgacık dönüşümü, herhangi bir sinyali çok aşamalı işlemden geçirerek alt-sinyallere dönüştürür. Dönüştürme işlemindeki asıl amaç, sinyal katsayılarını elde etmek (detaylı ve yaklaşık) ve elde edilen katsayıları tekrar bir araya getirerek sinyalin doğrusal kombinasyonunu elde etmektir. ADT (Ayrık Dalgacık Dönüşümü) ile iki çeşit dalgacık katsayısı elde edilmektedir; detaylı (D) ve yaklaşık (A). Bu dalgacık katsayıları aracılığıyla sinyal farklı çözünürlük ve frekans aralıklarında analiz edilebilmektedir. Yaklaşık katsayısı sinyalin düşük geçiren filtresinden (DGF) elde edilirken, detaylı katsayısı yüksek geçiren filtreden (YGF) elde edilmektedir. Düşük ve yüksek geçiren filtrelerin hesaplama adımları Denklem 1 ve Denklem 2'de verilmiştir.

$$
\begin{aligned}
& Y G F(S)=D_{1 i}=\sum t S(t) k(2 i-t) \\
& D G F(S)=A_{1 i}=\sum t S(t) k(2 i-t)
\end{aligned}
$$

Hesaplama işlemi sinyal istenilen seviyeye ayrıştırılıncaya kadar devam etmektedir. Bu çalışmada EEG sinyalleri 4 seviye ayrıştırılmış ve D1, D2, D3, D4 ve A4 dalgacık katsayıları elde edilmiştir.

\subsection{2. Özellikler (Features)}

Özellik çıkarım aşamasında sırasıyla en yüksek değer, en düşük değer, ortalama değer, logaritmik enerji entropi (LogEn) ve Higuchi Fraktal Boyutu olmak üzere beş farklı yöntem kullanılmış ver her biri aşağıda açıklanmıştır.

\section{a) En Yüksek Değer (Maximum Value)}

Bir fonksiyonun en yüksek değeri, o fonksiyonun grafik üzerinde ulaştığı en yüksek noktayı ya da tepeyi ifade etmektedir. Daha çok en yüksek kar ve en yüksek alan hesaplamalarında kullanılan en yüksek değer, sinyal işleme alanında bir zaman serisinin belirli bir aralıkta ulaştığ zirve noktasını ifade etmektedir. 


\section{b) En Düşük Değer (Minimum Value)}

Bir fonksiyonun en düşük değeri, grafiğin en düşük yerdeki doruk noktasıdır. Daha çok en düşük maliyet ve alan hesaplamalarında tercih edilmektedir. Sinyal işleme alanında ise bir zaman serisinin belirli bir aralıktaki en düşük noktasını ifade etmektedir.

\section{c) Ortalama Değger (Mean Value)}

Ortalama değer, N sayıdan oluşan bir zaman serisindeki sayıların ortalamasını ifade etmektedir. Zaman serisinde bulunan tüm sayılar toplanır ve toplamın $\mathrm{n}$ değerine bölünmesiyle ortalama değer elde edilir. Denklem 3 'te ortalama değerin hesaplanması verilmiştir.

$$
\text { OrtDeğer }=\frac{\left(A_{1}+A_{2}+A_{3}+\ldots \ldots+A_{N}\right)}{N}
$$

\section{d) Log Enerji Entropi (Log Energy Entropy)}

Log Enerji entropi Shannon entropinin bir parçası olup Denklem 4'te verilen şekilde hesaplanır [21]. Shannon entropi herhangi bir sistemdeki belirsizlik derecesini ölçmek için kullanılmaktadır.

$$
\operatorname{LogEn}(x)=\sum_{i=0}^{N-1}\left(\log _{2}\left(p_{i}(x)\right)\right)^{2}
$$

\section{e) Higuchi Fraktal Boyutu (Higuchi Fractal Dimension)}

Higuchi Fraktal Boyutu değerleri tıpkı EEG sinyalleri gibi durağan olmayan sinyallerdeki karmaşıklıkları ölçmek için kullanılan bir yöntemdir. Çok az sayıda veri olsa dahi başarılı sonuçlar üretebilen bir yöntem olmasının yansıra hızlı ve doğrusal olmayan hesaplama yapabilmektedir [2223]. HFB, uzunluğu $N$ olan sonlu bir zaman serisini $\{a(1)$, $a(2), a(3) \ldots a(N)\}$ ilk olarak $k$ uzunluğundaki başka bir zaman serisine Denklem 5 'te verilen formül ile bölerek yeni bir zaman serisini meydana getirir.

$A_{k}^{m}: a(m), a(m+k), a(m+2 k), \ldots, a\left(m+\left[\frac{N-m}{k}\right] k\right)(5)$

$m$ değeri $1,2,3, \ldots k$ sabitine kadar değer almaktadır. $k$ tane zaman serisi elde edildikten sonra herbir zaman serisinin uzunluğu $L_{m}(k)$ Denklem 6'daki gibi hesaplanır.

$$
\begin{aligned}
& L_{m}(k) \\
& =\left\{\left[\sum_{i=1}^{\left[\frac{N-m}{k}\right]}|x(m+i k)-x(m+(i-1)) k|\right] \frac{N-1}{\left[\frac{N-m}{k}\right] k}\right\} \\
& k
\end{aligned}
$$

$L_{m}(k)$ değerinin ortalamasının hesaplanmasıyla HFB değeri elde edilir. Ortalama hesaplama adımı Denklem 7'de verilmiştir.

$$
H F B=\frac{1}{K} \sum_{M=1}^{K} L_{m}(k)
$$

Özelliklerin elde edilmesinin ardından etkili EEG kanallarının belirlenmesi amacıyla KDVM (Karesel Destek Vektör Makineleri) ile sınıflandırılmıştır.

\section{SINIFLANDIRMA BAŞARIMLARI (CLASSIFICATION ACCURACIES)}

Çalışmada 32 EEG kanalından da özellikler elde edilmiş ve bu özellikler doğrusal olmayan destek vektör makineleri kullanılarak sınıflandırılmıştır. Destek vektör makinesi için Gaussian radyal tabanlı fonksiyon [24] kullanılmış ve $C$ ceza parametresi göz önünde bulundurulmuştur. Ceza parametresi tıpkı [8] numaralı çalışmadaki gibi $\mathrm{C}=\left[2^{-10}, 2^{-}\right.$ $\left.8, \ldots, \ldots, 2^{8}, 2^{10}\right]$ uzayında olacak şekilde optimize edilmiştir. Her EEG kanalı için 25 adet özellik elde edilmiş ve toplamda destek vektör makinesi için giriş vektör değeri $32 \times 25$ olacak şekilde 800 adet özellik elde edilmiştir. Sınıflandırmanın başarım performansı 10-katlı çapraz

\begin{tabular}{|c|c|c|c|}
\hline $\begin{array}{c}\text { EEG } \\
\text { Kanalı }\end{array}$ & $\begin{array}{c}\text { Pozitif } \\
(\%)\end{array}$ & $\begin{array}{c}\text { Negatif } \\
(\%)\end{array}$ & $\begin{array}{c}\text { Ortalama } \\
(\%)\end{array}$ \\
\hline Fp1 & $\% 83$ & $\% 89$ & $\% 86$ \\
\hline Fp2 & $\% 73$ & $\% 78$ & $\% 76$ \\
\hline F3 & $\% 78$ & $\% 75$ & $\% 77$ \\
\hline F4 & $\% 74$ & $\% 71$ & $\% 73$ \\
\hline F7 & $\% 76$ & $\% 68$ & $\% 72$ \\
\hline F8 & $\% 77$ & $\% 71$ & $\% 74$ \\
\hline FC1 & $\% 74$ & $\% 65$ & $\% 70$ \\
\hline FC2 & $\% 68$ & $\% 73$ & $\% 71$ \\
\hline FC5 & $\% 66$ & $\% 70$ & $\% 68$ \\
\hline FC6 & $\% 83$ & $\% 76$ & $\% 80$ \\
\hline C3 & $\% 87$ & $\% 62$ & $\% 75$ \\
\hline $\mathrm{C4}$ & $\% 82$ & $\% 84$ & $\% 83$ \\
\hline CP1 & $\% 83$ & $\% 78$ & $\% 81$ \\
\hline CP2 & $\% 72$ & $\% 72$ & $\% 72$ \\
\hline CP5 & $\% 81$ & $\% 86$ & $\% 84$ \\
\hline CP6 & $\% 72$ & $\% 70$ & $\% 80$ \\
\hline T7 & $\% 85$ & $\% 75$ & $\% 80$ \\
\hline T8 & $\% 78$ & $\% 73$ & $\% 76$ \\
\hline P3 & $\% 76$ & $\% 72$ & $\% 74$ \\
\hline P4 & $\% 74$ & $\% 77$ & $\% 76$ \\
\hline P7 & $\% 89$ & $\% 78$ & $\% 84$ \\
\hline P8 & $\% 63$ & $\% 62$ & $\% 62$ \\
\hline PO3 & $\% 62$ & $\% 75$ & $\% 69$ \\
\hline PO4 & $\% 72$ & $\% 60$ & $\% 66$ \\
\hline $\mathbf{P z}$ & $\% 82$ & $\% 81$ & $\% 82$ \\
\hline 01 & $\% 65$ & $\% 75$ & $\% 70$ \\
\hline $\mathbf{O 2}$ & $\% 63$ & $\% 50$ & $\% 57$ \\
\hline $\mathbf{O z}$ & $\% 65$ & $\% 78$ & $\% 72$ \\
\hline AF3 & $\% 75$ & $\% 80$ & $\% 78$ \\
\hline AF4 & $\% 77$ & $\% 74$ & $\% 76$ \\
\hline Ortalama & $\% 75$ & $\% 73$ & $\% 74$ \\
\hline
\end{tabular}
doğrulama ile ölçülmüş ve her bir EEG kanalının başarımları Tablo 1'de belirtilmiştir.

Tablo 1. Pozitif-negatif duyguları sınıflandırma bașarımları (Classification accuracies for positive-negative emotions) 
Tablo 1'den de anlaşılacağı üzere bazı EEG kanallarının başarım oranı diğer kanallara göre daha iyi sonuç üretmiş ve bu oran \%80'in üstüne kadar çıkmıştır. \%80'in üzerinde başarım sağlayan kanallar etkili olarak değerlendirilmiş ve bu kanallar Fp1, FC6, C4, CP1, CP5, CP6, T7, P7 ve Pz olacak şekilde gözlemlenmiştir. Ayrıca başarılı EEG kanallarına bakıldığında, beynin sol lobunda bulunan elektrotların (Fp1, CP1, CP5, P7 ve T7) sağ lobunda bulunan elektrotlardan (FC6, C4 ve CP6) daha başarılı sonuç ürettikleri görülmektedir. Ek olarak, beynin art kafa (occipital) ve orta (central) bölgelerinin diğer bölgeler daha etkisiz oldukları söylenebilir. Tablo 2'de kafatasında bulunan bölgelerin pozitif ve negatif duygular için ortalama başarımları verilmiştir.

Tablo 2. Kafatasında bulunan bölgelerin ortalama başarımları (Average performances of zones in the skull)

\begin{tabular}{|c|c|}
\hline $\begin{array}{c}\text { Kafatası } \\
\text { Bölgeleri }\end{array}$ & $\begin{array}{c}\text { Pozitif Duygu } \\
(\boldsymbol{\%})\end{array}$ \\
\hline Ön ve Alın Bölgesi & $\% 76,5$ \\
\hline Art kafa Bölgesi & $\% 66,3$ \\
\hline Şakak Bölgesi & $\% 78$ \\
\hline Yan kafa Bölgesi & $\% 74$ \\
\hline Orta Bölge & $\% 79$ \\
\hline
\end{tabular}

Tablo 2'de bulunan verilere göre en etkili EEG bölgelerinin orta, ön ve alın bölgesi ve şakak bölgeleri olduğu görülmektedir. Bireysel olarak EEG kanallarının başarımları \%80'in üzerindeyken bu oran, bölgeler ele alındığında \%70’lere kadar gerilemiştir.

Önerilen yönteme ait log kaybı sonuçları verilmiş ve çalışmadaki sınıflandırıcının performansı log-kaybına göre değerlendirilmiştir. Tablo 3'te her bir EEG kanalının duygulara göre sergiledikleri log kaybı sonuçları verilmiştir.

Tablo 3. EEG kanallarının göstermiş olduğu log-kaybı sonuçları (Log-loss results of each EEG channel)

\begin{tabular}{|c|c|c|}
\hline $\begin{array}{c}\text { EEG } \\
\text { Kanalı }\end{array}$ & $\begin{array}{c}\text { Pozitif } \\
\text { Log-Kaybı }\end{array}$ & $\begin{array}{c}\text { Negatif } \\
\text { Log-Kaybı }\end{array}$ \\
\hline Fp1 & 0.1863 & 2.2073 \\
\hline Fp2 & 0.3147 & 1.5141 \\
\hline F3 & 0.2485 & 1.3863 \\
\hline F4 & 0.3011 & 1.2379 \\
\hline F7 & 0.2744 & 1.1394 \\
\hline F8 & 0.2614 & 1.2379 \\
\hline FC1 & 0.3011 & 1.0498 \\
\hline FC2 & 0.3857 & 1.3093 \\
\hline FC5 & 0.4155 & 1.2040 \\
\hline FC6 & 0.1863 & 1.4271 \\
\hline C3 & 0.1393 & 0.9676 \\
\hline C4 & 0.1985 & 1.8326 \\
\hline CP1 & 0.1863 & 1.5141 \\
\hline CP2 & 0.3285 & 1.2730 \\
\hline CP5 & 0.2107 & 1.9661 \\
\hline CP6 & 0.3285 & 1.2040 \\
\hline T7 & 0.1625 & 1.3863 \\
\hline T8 & 0.2485 & 1.3093 \\
\hline P3 & 0.2744 & 1.2370 \\
\hline P4 & 0.3011 & 1.4697 \\
\hline P7 & 0.1165 & 1.5141 \\
\hline
\end{tabular}

\begin{tabular}{|c|c|c|}
\hline P8 & 0.4620 & 0.9676 \\
\hline PO3 & 0.4780 & 1.3863 \\
\hline PO4 & 0.3285 & 0.9163 \\
\hline Pz & 0.1985 & 1.6607 \\
\hline O1 & 0.4308 & 1.3863 \\
\hline O2 & 0.4620 & 0.6931 \\
\hline Oz & 0.4308 & 1.5141 \\
\hline AF3 & 0.2877 & 1.6094 \\
\hline AF4 & 0.2614 & 1.3471 \\
\hline Ortalama & 0.2877 & 1.3093 \\
\hline
\end{tabular}

Sınıflandırma değeri 1'e yaklaştıkça log kaybı 0'a yaklaşmaktadır. İyi bir sınıflandırıcının log kaybı 0 olmalı ve değer ne kadar 0'a yakınsa sınıflandırma o kadar başarılı olmaktadır. Şekil 6 ve Şekil 7'de pozitif ve negatif duyguların ortalama log kaybı skorları verilmiştir.

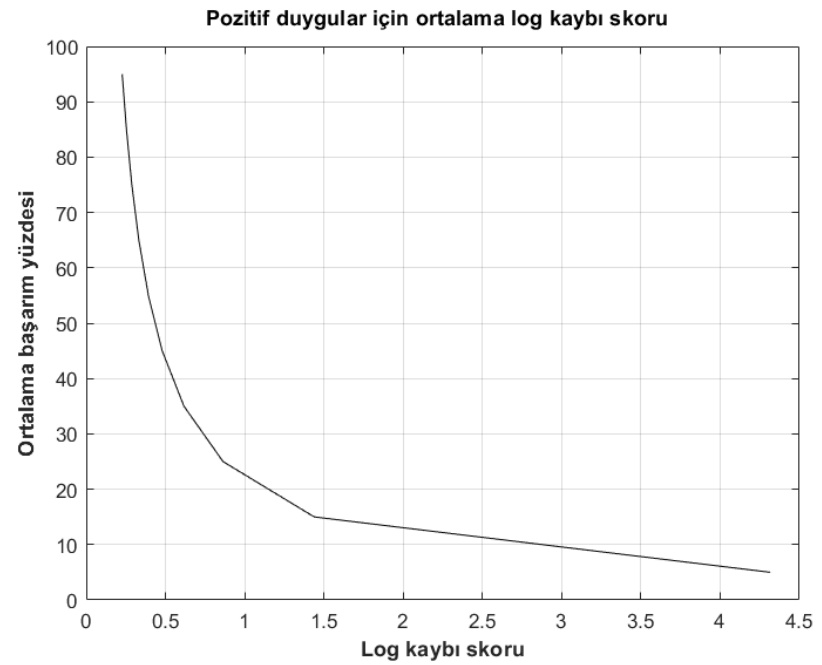

Şekil 6. Pozitif duyguların sergilemiş olduğu log kaybı skorları (Log-loss scores for positive emotions)

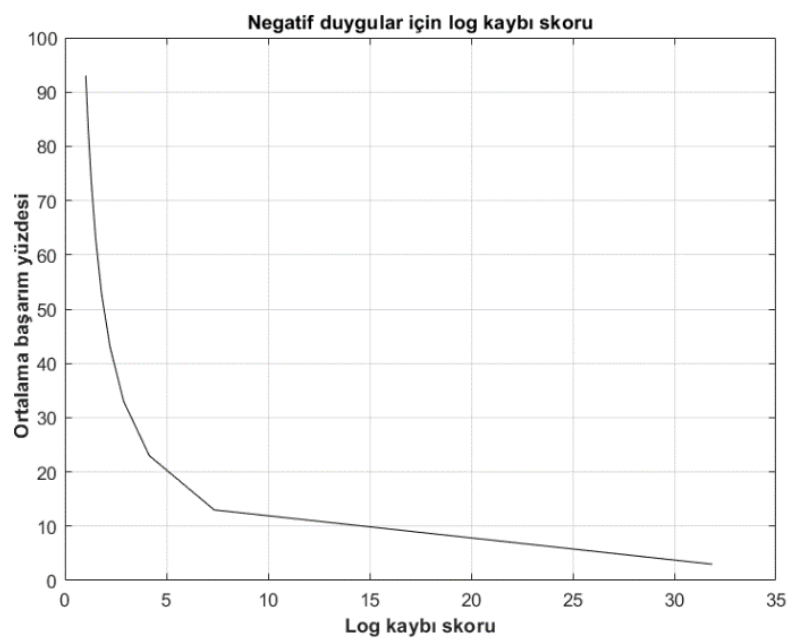

Şekil 7. Negatif duyguların sergilemiş olduğu log kaybı skorlar1 (Log-loss scores for positive emotions)

Şekillerden de anlaşılacağı üzere başarım yüzdesi düştükçe log kaybı skorlarında artış görülmektedir. 


\section{SONUÇ (CONCLUSION)}

$\mathrm{Bu}$ çalışmada EEG verileri kullanılarak duygu analizi yapılmıştır. Çalışma kapsamında hazır EEG verileri kullanılmış ve 32 EEG kanalının duygu analizinde etkisinin araştırılması amaçlanmıştır. İlk olarak önişlemden geçirilmiş EEG verileri üzerinde dalgacık dönüşümü işlemi yapılmış ve farklı EEG frekansları aralığında çalışmaya zemin hazırlanmıştır. Ardından her EEG kanalına ait dalgacık katsayılarından (detaylı ve yaklaşık) özellikler elde edilmiştir. Özelliklerin elde edilmesinin ardından pozitif-negatif duyguların ayrımı için destek vektör makineleri kullanılmış ve başarım oranı \%80'in üstünde olanlar etkili olarak değerlendirilmiştir. Ayrıca yapmış olduğumuz çalışmanın sınıflandırma performansı literatürde DEAP veriseti kullanılarak gerçekleştirilen çalışmalarla kıyaslanmış ve sonuçları Tablo 4'te verilmiştir.

Tablo 4. Önerilen yöntemin diğer yöntemlerle kiyaslanması (Comparison of proposed method with other methods)

\begin{tabular}{|c|c|}
\hline Çalışmalar & Ortalama Başarım \\
\hline$[\mathbf{8}]$ & $\% 94,98$ \\
\hline$[\mathbf{9}]$ & $\% 67,11$ \\
\hline$[\mathbf{1 0}]$ & $\% 66,01$ \\
\hline$[\mathbf{1 1}]$ & $\% 52,73$ \\
\hline$[\mathbf{1 5}]$ & $\% 83$ \\
\hline$[\mathbf{1 6}]$ & $\% 82,21$ \\
\hline Bu çalışma & $\% 74$ \\
\hline
\end{tabular}

Tablo 4'ten de anlaşılacağı üzere önerdiğimiz yöntemin ortalama performansı literatürdeki bazı çalışmalardan daha etkili olmuş ancak bazılarına göre ise etkisiz olmuştur. Çalışmanın başarımı seçilen yöntemlere, sınıflandırıcılara ve kullanılan EEG kanallarına göre değişiklik göstermekte ve bundan dolayı çok sayıda çalışmada çok sayıda farklı sonuçlar görülmektedir.

Çalışmanın ileriki aşamalarında;

- Farklı dalgacık filtreleri (Symlet, Morlet, Ampirik Kip Ayrışımı vb.) ya da farklı seviyeler tercih edilebilir.

- Kullanılan özellik çıkarım aşamasında çeşitli bilgi ölçüm yöntemlerine (Örnek entropi, çok-ölçekli entropi, Shannon entropi vb.) ve istatistiksel tekniklere (varyans, standart sapma, en küçük kareler, vb.) başvurulabilir.

- Farklı sınıflandırıcılar üzerinde (KNN - K En Yakın Komşu, YSA - Yapay Sinir Ağları, DÖ - Derin Öğrenme, RO - Rastgele Orman, vb) durulabilir ve başarımları karşılaştırılabilir.

- Bu çalıșmada kullanılan sınıflandırmanın parametreleri değiştirilip (çekirdek fonksiyonu ve ceza kümesinin değiştirilmesi) değiştirilip, çalışma kıyaslanabilir.

- Sınıflandırma üzerine yoğunlaşılması yerine özellik çıkarım yöntemlerinin EEG kanalları üzerindeki etkisi araştırılabilir ve karşılaştırılabilir.
- Özellik seçim yöntemlerine (t-skor, ki kare, ardışık ileri yönde veya geri yönde seçim, vb.) başvurulabilir ve gereksiz olan özeliklerin elenmesiyle sınıflandırma başarımı test edilebilir.

- Dalgacık dönüşümüne başvurulmadan özellik çıkarım yapılabilir ve dalgacık dönüşümünün sınıflandırma üzerindeki etkisi incelenebilir.

- Çalışmada ön işlemden (gürültülerden temizlenmiş) veriler kullanılmıştır. Gürültü içeren verilerin kullanılmasıyla bir çalışma gerçekleştirilebilir.

- Sinyalleri önişlemden geçirmek için başka bir filtreleme yöntemleri tercih edilebilir.

\section{KAYNAKLAR (REFERENCES)}

[1] M. Naji, M. Firoozabadi, P. Azadfallah, "Emotion Classification During Music Listening from Forehead Biosignals", Signal, Image and Video Processing, 9(6), 1365-1375, 2015.

[2] A. Turnip, A. I. Simbolon, M. F. Amri, P. Sihombing, R. H. Setiadi., E. Mulyana, "Backpropagation Neural Networks Training for EEG-SSVEP Classification of Emotion Recognition", Internetworking Indenosia Journal, 9(1), 53-57, 2017.

[3] S. J. Westerman, P. H. Gardner, E. J. Sutherland, "Usability Testing Emotion-Orianted Computing Systems: Psychometric Assessment", HUMAINE Deliverable, 1-53, 2006.

[4] M. Lhommet, S. C. Marsella, "Expressing Emotion through Posture and Gesture", The Oxford Handbook of Affective Computing, Oxford Library of Psychology, Oxford, 2015.

[5] T. B. Alakuş, İ. Türoğlu, "EEG Based Emotion Analysis Systems", Türkiye Bilişim Vakfi Bilgisayar Bilimleri ve Mühendisliği Dergisi, 11(1), 26-39, 2018.

[6] W. Szwoch, Using Physiological Signals for Emotion, Sopot, Poland, 2013

[7] J. Pan., Y. Li., J. Wang, “An EEG-Based Brain-Computer Interface for Emotion Recognition”, 2016 International Joint Conference on Neural Networks, Canada, 2063-2067, 2016.

[8] Y. Zhang, X. Ji, S. Zhang, "An Approach to EEG-Based Recognition Using Combined Feature Extraction Method", Neuroscience Letters , 633, 152-157, 2016.

[9] C. Shahnaz, S. Bin-Masud, M. S. Hasan, "Emotion Recognition Based on Wavelet Analysis of Emprical Mode Decomposed EEG Signals Responsive to Music Videos”, Region10 Conference, 424-427, 2016.

[10] N. Kumar, K. Khaund, S. M. Hazarika, "Bispectral Analysis of EEG for Emotion Recognition", Procedia Computer Science, 84, 31-35, 2016.

[11] S. Jirayucharoensak, S. P. Ngum, P. Israsena, "EEG-Based Emotion Recognition Using Deep Learning Network with Principal Component Based Covariate Shift Adaptation", The Scientific World Journal, 2014.

[12] S. Wu, X. Xu, L. Shu, B. Hu, "Estimation of Valence of Emotion Using Two Frontal EEG Channels", IEEE International Conference on Bioinformatics and Biomedicine, 1127 - 1130, 2017. 
[13] P. Ekman, "An Argument for Basic Emotions", Cognition and Emotion, 6(3-4), 169-200, 1992.

[14] J. A. Russel., "Core Affect and Psychological Construction of Emotion”, Psychological Review, 110(1), 145-150, 2003.

[15] Q. Zhang,, X. Chen, Q. Zhan, T. Yang, S. Xia, "Respiration-Based Emotion Recognition with Deep Learning", Computers in Industry, 92(2017) 84-90, 2017.

[16] A. Mert, A. Akan, "Emotion Recognition Based on TimeFrequency Distribution of EEG Signals Using Multivariate Synchrosqueezing Transform", Digital Signal Processing, 81(2018), 152-157, 2018.

[17] L. Xin, S. Xiao-Qi, Q. Xiao-Ying, S. Xiao-Feng, "Relevance Vector Machine Based EEG Emotion Recognition", 2016 Sixth International Conference on Instrumentation \& Measurement, Computer, Communication and Control, China, 293-297, 2016.

[18] B. Krisnandhika, A. Faqih, P. D. Pumamasari, B. Kusumoputro, "Emotion Recognition System Based on EEG Signals Using Relative Wavelet Energy Features and a Modified Radial Basis Function Neural Networks", 2017 International Confference on Consumer Electronics and Devices, London, 50-54, 2017.
[19] S. Aydın, H. M. Saraoğlu, S. Kara, "Log Energy Entropy-Based EEG Classification with Multilayer Neural Networks in Seizure", Annals of Biomedical Engineering, 37(12), 2626-2630, 2009.

[20] S. Koelstra, C. Mühl, M. Soleymani, "DEAP: A Database for Emotion Analysis: Using Physiological Signals", IEEE Transactions on Affective Computing, 3(1), 18-31, 2012.

[21] T. B. Alakuş, I. Turkoglu, EEG Verilerinden İşaret İşleme ve Sınıflandırma Teknikleri Kullanılarak Duygu Tahmini, Yüksek Lisans Tezi, Fırat Üniversitesi, Fen Bilimleri Enstitüsü, 2018.

[22] Accardo, M. Affinito, M. Carrozzi, and F. Bouqet, 'Use of the Fractal Dimension for the Analysis of Electroencephalographic Time Series", Biological Cybernetics, 77(5), 339-350, 1997.

[23] A. Al-Nuaimi, E. Jammeh, L. Sun, and E. Ifeachor, "Higuchi Fractal Dimension of the Electroensephalogram as a Biomarker for Early Detection of Alzheimers Disease, IEEE Engineering in Medicine and Biology Society Annual Conference, 2320-2324, 2017.

[24] Calp, M. H., "Medical Diagnosis with a Novel SVM-CoDOA Based Hybrid Approach", BRAIN. Broad Research in Artificial Intelligence and Neuroscience, 9(4), 6-16, (2018). 